\title{
EL ESPACIO NOVELESCO EN CONJETURAS DE LA MEMORIA DE MI TRIBU DE JOSÉ DONOSO
}

\author{
Novel-Oriented Space in José Donoso's Conjeturas sobre la memoria de mi \\ tribu
}

\section{RESUMEN}

Este trabajo explora la emergencia de un espacio novelesco en las Conjeturas sobre la memoria de mi tribu de José Donoso, problematizando así su estatuto genérico. El proceso de novelación se consolida a través de la imagen de un velo negro, que metaforiza una poética escritural en constante estado de opacidad. Donoso oscila entre las figuras del curador y la del escritor, privilegiando esta última por medio de recursos intertextuales que acentúan la tesitura translúcida de las Conjeturas, obra indispensable en la novelística del autor.

Palabras claves: José Donoso, espacio novelesco, conjeturas, escritura, velo negro.

\section{ABSTRACT}

This study explores the rise of a novel-oriented space in José Donoso's Conjeturas sobre la memoria de $m i$ tribu. The novel-ridden process consolidates itself through the image of a black veil, which can be read as metaphor of a poetics in a constant state of opacity. Donoso fluctuates between the figures of a curator and a writer, stressing the latter and the intertextual resources that draw our attention to the translucent texture of his Conjeturas, a milestone in the author's narrative work.

\section{UNIVERSUM}

Revista de Humanidades y Ciencias Sociales

\section{ANDRÉS FERRADA \\ AGUILAR}

Universidad de Playa Ancha, Valparaíso, Chile/ Universidad de Chile, Santiago de Chile, Chile.

Correo electrónico:

aferrada@upla.cl

ORCID: 0000-0001-8863-5462

ResearchGate:

Scholar.google:

Academia.edu:

Dedico este estudio a la memoria de Leonidas Morales Toro, académico de la Universidad de Chile, en gratitud y en reconocimiento por su visión crítica de la literatura.

Keywords: José Donoso, novel-oriented space, conjectures, writing, black veil.

Artículo recibido el 3 de septiembre, 2019. Aceptado el 11 de mayo, 2020.

Web: http://universum.utalca.cl | ISSN: 0716-498X - 0718-2376 


\section{INTRODUCCIÓN}

El presente trabajo examina la novelación de las historias familiares en Conjeturas sobre la memoria de mi tribu (1996), de José Donoso. Salen a la luz después de un largo período de revisiones y, especialmente, especulaciones. La novelación de estas conjeturas se inicia en el primer capítulo, con reflexiones metanarrativas por medio de las cuales Donoso explora su propia escritura. En los siguientes, el autor cuestiona la veracidad de las historias de la familia Donoso Yáñez, y la genealogía de sus mitos. Es en el penúltimo capítulo donde apreciamos la consolidación de este proceso con el entrelazamiento de tres conjeturas sobre una tía abuela del autor. Nuestro objeto gira en torno a este espacio conjetural, donde el autor apela a las "prerrogativas del novelista" (Donoso, Artículos 204), dejando en segundo plano obsesiones biográficas o la búsqueda empírica de la verdad.

Sin temor a equivocarnos, es posible sostener que de todos los trabajos de Donoso, las Conjeturas es el que menos atención crítica ha recibido, en comparación con su obra narrativa. Y el punto es que, curiosamente, estas Conjeturas han sido frecuentemente separadas de su producción novelística, en circunstancias que, creemos, ellas constituyen un hito relevante de esa zona escritural.

Algunas aproximaciones a las Conjeturas destacan el pacto que ellas realizan con aspectos biográficos e identitarios, valorando así la imbricación del texto con la referencialidad. Martín Lombardo, indica que, según Philippe Lejeune, existen dos condiciones que fundamentan el discurso autobiográfico: "en primer lugar, la identidad entre autor y narrador; en segundo lugar la identidad entre narrador y personaje principal" (152). Dicho de otro modo, y como plantea Leonidas Morales cuando se refiere a los géneros referenciales, "el autor y sujeto de la enunciación son el mismo: coinciden" (Escritura 11).

Por su parte, Rodrigo Cánovas piensa que al "leer esta historia, sorprende la parquedad y la escasa intimidad autobiográfica que hay en ella" (56). Sin embargo, y si pensamos en el protagonismo que Donoso confiere al rol del 
escritor en las Conjeturas, esta sobriedad no sorprende. No quiere hablar de sí mismo desde la obscenidad de la identidad, sino desde de la escenificación de su figura de escritor. Donoso ofrece así un contundente argumento contra la crítica biográfica o histórica, gestada desde el Romanticismo. Y también contra las bases cartesianas que apoyaron esa mirada a la literatura.

Proponemos que las Conjeturas instan un proceso de novelación a partir de especulaciones imaginativas que revelan cómo Donoso piensa el género novela y, desde aquí, el diseño de sus conjeturas. En este sentido, el autor se debate entre dos oficios, la curaduría y la escritura. El primero le ofrece articular las memorias de su tribu desde una lógica de la restauración; el segundo, en tanto, le permite crear un espacio literario animado por la imagen de un velo negro que se conecta con otras obras de Donoso y con la de un antecesor suyo, el novelista norteamericano Nathaniel Hawthorne.

El estatuto genérico de las Conjeturas es versátil. Combina elementos referenciales y ficticios en una relación dialéctica que nos mantiene en vilo; oscilando entre un campo discursivo y otro. Si bien los géneros referenciales poseen una filiación "extratextual de diversa identidad: cultural, social, político, literario, artístico, biográfico, etc.”, estos también se construyen en base a los "grandes modelos estéticos" (Morales 11-12). Esta inclinación estética, en conjunto con la tesitura literaria, se hacen evidentes en el capítulo 7, el cual sintetiza las tensiones extratextuales con las obsesiones creativas del autor. Se funden y confunden, encareciendo el ámbito de la ficción. Ahora bien, Jean-Marie Schaeffer considera que la "dificultad del problema de la identidad genérica de las obras literarias no se debe únicamente al hecho de que los textos sean actos semióticamente complejos, va también ligada al hecho de que las obras [...] tienen un modo de ser histórico" (91). Piensa Schaeffer en una historia de "contextos" socio-culturales amplios.

Creemos que en el caso de Donoso su persona, que compromete su idiosincrasia y subjetividad, es, de todas las historias, la que mejor señala una ruta para comprender sus Conjeturas. Esta persona privilegia sus máscaras, pero no las íntimas, sino aquellas con las que encubre y ensaya su escritura. Donoso se muestra reacio a que su escritura sea un rostro. Al respecto, 
y teniendo en cuenta la compleja fisonomía genérica de las Conjeturas, reconocemos el papel que en ellas juega el ensayo, como clase de discurso y gesto experimental. El "verdadero ensayista está, por debajo de esa ocupación visible [la lectura de otro escrito, la contemplación de una obra artística o la íntima resonancia de una idea ajena], trabajando consigo mismo" (32), subraya Martín Cerda. Donoso se ensaya a sí mismo y, al hacerlo, su escritura.

Vinculando ahora este ejercicio con la autobiografía en las Conjeturas, concordamos con Cerda cuando especifica que nadie escribe "un texto autobiográfico sólo para confesar su posible desorden interno, sino que siempre lo hace para ordenar mediante un relato coherente esa confusión que lo atormenta, y que, a la postre, amenaza con alterarlo" (116). Sin embargo, y en el espacio literario donosiano, la alteración no amedrenta al autor. Al contrario, la busca y promueve por medio del enmascaramiento y, como dijimos, el acento que otorga a la imagen del velo en las Conjeturas. En su etimología, "conjeturar" remite a una actividad vigorosa que, a diferencia de los actos de reflexión y su parsimonia, impulsa el pensamiento en seguidillas de asociaciones libres. La elasticidad de este vigor ensayístico moviliza una escritura que oscila entre la memoria de una tribu y su imaginación literaria.

\section{JOSÉ DONOSO: ENTRE LA VERDAD DEL CURADOR Y LA IMAGINACIÓN DEL ESCRITOR}

Salvo hacia el final, Donoso evade encauzar la escritura por el sendero de la ficción, vacilando productivamente entre las imágenes del pasado y su representación. Bien lo explica el autor en el capítulo que abre las Conjeturas, "La trama de los orígenes": "Desde niño aceché, esperando con malsana avidez, la coyuntura propicia para ceder a la tentación de escarbar en mi memoria tribal y reordenar su arquitectura para reconocerme en ella" (15). Conviene notar que Donoso entiende el acervo imaginal como un espacio dúctil, susceptible de alteración, y a él mismo como un arquitecto que desea reflejarse en su propia obra. Surge aquí un índice de la figuración biográfica que, a fin de cuentas, también experimenta una ficcionalización a través de 
una "pose". Esta, de acuerdo a Leonidas Morales y en el contexto de los diarios del autor, "es para donoso la estrategia mediante la cual es posible dar forma a una sinceridad que supere la expresión 'pura y directa', ciega en último término, anárquica, mediante una sinceridad como construcción (o codificación) de verdad" ("Diario" 243). Cabe responder, entonces, que motivaría este posicionamiento de y frente a la verdad en el espacio escritural de las Conjeturas.

Una respuesta aparece al inicio, cuando el autor se refiere a sus lecturas juveniles, advirtiendo que en ellas "el dolor causado por la ambigüedad social es uno de los temas que en los novelistas han dado mayores frutos, una de las 'fallas geológicas' con pedigree literario más sólido" (17). Destaca, entre otros, a Jane Austen, Dostoievski, Proust, James y Woolf, que manifestaron esta "falla" en carne propia y en sus creaciones. De allí, en parte, su cercanía con estos escritores, que además de suministrar modelos estéticos, fueron capaces de reinventar esta conciencia de clase en sus novelas. Donoso, por su parte, reconoce que es esta ambigüedad la que anima sus conjeturas, y parte de su literatura. Por lo tanto, y a diferencia de sus antecesores, renunciará "saldar" esta falla. Construye la pose de un sujeto que desea identificarse con un lugar, atando los cabos sueltos de una genealogía de "tribus muy distintas" y de "origen oscuro" (21). Sin embargo, el autor es consciente que el arribo a una historia familiar transparente o desmitificada conlleva el cese de la palabra. Surge así otro sentido ambiguo en las Conjeturas. Una vez resuelta la arquitectura de la memoria de los antepasados, y explicadas sus tensiones y endogamias, el juego de la fantasía se detiene.

Compiten en las Conjeturas las figuras del curador y el escritor. Una intentará habilitar la memoria, levantando una puesta en escena coherente, similar a la de una exhibición museal. No es difícil imaginar a Donoso barajando distintas tramas para los retratos de sus antepasados: cronológicas, sanguíneas, afectivas. Observa, por ejemplo, las fotografías sobre su escritorio, creando nexos que dan cuenta de una constelación entre seres dispares, e incluso antagónicos. El escritor, en cambio, oscurecerá las zonas iluminadas de la memoria, deshaciendo las lógicas de la curaduría, precisamente para "ver" 
mejor los intersticios que tributan a la ficción. Otros artistas en la narrativa de Donoso demuestran una vacilación similar. ${ }^{1}$ Desean crear una obra, conscientes de que ese acto, realizado mediante un saber o una poética que "ilumina" la composición, clausura la opacidad, necesaria para el despliegue de la fantasía. En su dedicatoria a "las mujeres de su descendencia", Donoso las invita a no olvidar, bajo el convencimiento de que "contar" es "inventar otra vez más". ¿Quién habla aquí, sino la voz del novelista que admite, enfático, "no [saber] vivir fuera de la escritura..."? (Cit. en Huidobro, 25).

Cuando el trabajo del curador parece haber iluminado las conexiones, y secretos, de la genealogía Donoso Yáñez, el autor borronea lo esclarecido, buscando otros resquicios. Esta redición de hechos históricos y familiares sobresale a lo largo de las Conjeturas. Aun así, Donoso dedica el capítulo más extenso, "Los cueros negros", a ensombrecer un episodio clave en sus memorias, que metaforiza la complicidad entre un aspecto de la realidad, la fisura social, y su interpretación imaginativa. A diferencia de los capítulos anteriores, aquí la figura del escritor se antepone a la del curador, el espacio literario se problematiza, y emergen conjeturas que reflejan una poética de transformación al interior de un texto que "posa" con el hábito de la referencialidad. Antes de continuar, es necesario acotar el episodio en cuestión. La historia gira en torno a una tía abuela de José Donoso, Marta Donoso Henríquez, "monja de clausura en las Capuchinas de la calle Lira" (173), Santiago. Sor Bernarda no solo se encuentra recluida, sino que aparece en el recuerdo de Donoso como "una espantosa figura femenina con la cara cubierta por un velo negro" (174). Desde su ingreso al convento en la década de 1880 y hasta 1934, año en que Donoso y su padre la visitan, no existe testimonio de alguien que haya visto su rostro.

Sobre este velo Donoso crea una serie de conjeturas que acentúan las "prerrogativas del novelista" (Artículos 204), insinuadas en capítulos anteriores. Estas prerrogativas, "observar, escuchar, preguntar" (205), favorecen la

1 Destaco a la Manuela en El lugar sin límites (1966), el novelista Julio Méndez en El jardín de al lado (1981) y el cantautor Mañungo Vera en La desesperanza (1986). 
aparición de fantasías que, en último término, alientan y justifican la tarea del escritor. Surge junto a esas fatasías una imagen que desajusta las historias oficiales, abriendo la posibilidad de una "novel acción". No nos referimos a que este velo, y su enigmática portadora, constituyan material para una novela futura, o un proyecto narrativo, como de hecho sugiere Donoso - "muchos años después sentí una creciente obsesión por la capuchina velada, por escribir una historia que podría ser la suya, combinando lo que me dictaba la fantasía con los escasos elementos de realidad que sobre ella se conservaban" (175, énfasis del texto)—, sino a la idea de que un proceso de "novelación" se escribe e inscribe al interior mismo de las Conjeturas. Esta desviación hacia ese "contar que es inventar", como indica Donoso en la dedicatoria, tensiona la veracidad de los pocos recuerdos que quedan de Sor Bernarda. "Nadie se acordaba de nada: éstos eran tiempos difíciles, ponderaban [los pocos ancianos de la familia que iban quedando], sin tranquilidad para atender a los discutibles vientos de santidad que en otras épocas, se decía, soplaron en la familia" (175). En este sentido, Donoso se convierte en un inventor de recuerdos, restituyendo la memoria familiar a través de conjeturas que, proviniendo de un escritor y no de un filósofo, se inclinan hacia la ficción.

Esta inclinación crea un desequilibrio notable, reflejado en la recepción estética de la narración. Los lectores, y Donoso mismo, olvidamos provisionalmente la pregunta que motiva escarbar la biografía de Sor Bernarda - ¿De qué horrenda fechoría era culpable esa monja, para que estimaran necesario vigilarla como a una loca o a una delincuente?" (174)—, absorbidos, en cambio, por la atmósfera y la tesitura del relato. Así, la visita al convento puede leerse como una incursión neo-gótica donde las referencias a una modernidad de corte burgués — representada por la costumbre de jugar golf y el Nash que conduce el padre de Donoso - se diluyen entre las "sombras de los cuadros de grandes temas terroríficos [que] insinuaban cuerpos contorsionados por el martirio y facciones contrahechas por la violencia, la sangre y el sufrimiento" (174). La hagiografía visual se mezcla, además, con pasadizos secretos en un tono acústico que refleja las impresiones del niño: "Mi padre me hizo trepar, remolón, a la caverna del torno, donde rompí a 
llorar. Grité y pedí socorro en cuanto el torno, con una secuencia de chirridos, giró conmigo berreando adentro. [...]. Me estremeció un sacudón de terror" (174).

Con el paso del tiempo, y aparentemente desalentado, el autor confiesa: "La desaparición de Sor Bernarda me había dejado desguarnecido de espectros: se me había volado con sus ángeles sombríos a otra parte y ya no era cuestión de preguntar, buscar, indagar, porque ya nada, nunca, iba a tener respuesta" (177). En efecto, ante la imposibilidad de hacer una curaduría ceñida al pensamiento metódico, cuestionando e indagando, el escritor apela a los espectros de su imaginación. Comienza, en otras palabras, a conjeturar imaginariamente. La desnudez de recuerdos que Donoso lamenta en la cita es una pose que subraya el carácter referencial de las Conjeturas. Con esta postura el autor legitima la búsqueda de la verdad, sintiendo la pérdida de los nexos verificables que lo conectaban con su antepasada. No obstante, esta separación le permite recurrir, sin lamentaciones y con absoluto placer, a la imaginación literaria. Como tinta en el papel, las fantasías de Donoso se deslizarán a sus anchas a partir de un motivo central, el velo negro.

\section{"CORRER UN TUPIDO VELO..."}

Percibimos este giro en capítulos anteriores. En "La primera salida de Don Quijote", Donoso recuerda su "primera constelación fantástica" (6364), a partir de los versos infantiles que su madre recitaba. Y en "Mariposas" reconoce que el periodismo gráfico y las películas crearon un “eslabón en mi curiosidad por lo otro, lo que estaba fuera de casa, lo que sucedía no en el colegio sino en la imaginación" (110, énfasis del texto). En el capítulo que nos ocupa, en cambio, estos destellos son parte de una lucidez que alienta la escritura. Las narraciones, estima Donoso,

deben ser más que un acopio de datos entrelazados en la cadena del tiempo: es necesario cierto soplo para animar el cristal de la imaginación de modo que, no transparentes sino translúcidas, retengan una parte de la mirada, rechazando su función de transparencia total para que así la imagen retenida de paso a otra imagen tan completa que se desintegre al tocar el desorden lineal de la realidad (173). 
Ahora bien, ¿qué conjeturas se levantan a partir de esta poética narrativa? ¿Qué nuevos espectros aparecen en el cristal de la imaginación? Quien inspira estos desvíos es una de las hijas del matrimonio Donoso Henríquez.

Eugenia, hermana de Marta, enviuda joven al cuidado de dos hijos. Sus padres la reciben en Talca, pero huye y se casa con el Gringo Barrow, un norteamericano sureño que peleó en la Guerra de Secesión. Custodio, empleado afro-descendiente y amante de Eugenia, le ayuda a escapar. A partir de este espacio novelístico, nos interesa destacar sus efectos. Cuando el padre se entera de la huida, y de que Eugenia retribuye la ayuda de Custodio con juegos eróticos, exclama: “iLo que contó este negro, que no salga de aquí! ¡Es una mentira inmunda! ¡Es una degeneración pensar que este esclavo la tocó! Hay que callarlo todo, echarle tierra al asunto, correr un tupido velo... que nadie se entere" (209). Una consecuencia es la presencia del velo que encarna el silenciamiento de la verdad, o su tergiversación, motivo acuciante en la narrativa donosiana. ${ }^{2}$ Ejemplo de ello es el cuento "Paseo" (1960), cuya protagonista, tía del narrador, desaparece para siempre en la noche de una ciudad portuaria. Ante la insólita situación, que impugna el orden burgués, sus hermanos "comenzaron a construir un muro de olvido o indiferencia que lo cubriera todo para poder enmudecer sin necesidad de martirizarse haciendo conjeturas impotentes" (228). En El obsceno pájaro de la noche (1970), el oligarca Azcoitía, incapaz de tolerar la deformidad de su hijo, lo encierra en una hacienda, custodiado por sirvientes igualmente contrahechos. En Casa de campo (1978), en tanto, "Donoso deforma y parodia la expresión ['correr el velo'] y la utiliza como un leit motif a través de la novela” (Álvarez-Rubio 19). Sobre estos personajes, y tramas, cae el mismo velo de silencio que enclaustra a la monja capuchina. Más adelante veremos cómo la imagen del velo también se desliza intertextualmente.

2 Este motivo se convierte en un argumento central en varios ensayos y crónicas de José Donoso. Destaco, entre otros, "País 'desinflado"” (1987), "El paisaje borrado" (1987) y "La palabra traicionada” (1988), en José Donoso: diarios, ensayos, crónicas (2009), Ed. Patricia Rubio. 
En las obras referidas observamos una voluntad de poder que impone una historia oficial en torno a un vergonzante hecho familiar. Por su parte, Donoso decide el curso de su escritura con una voluntad artística que se sobrepone a exigencias externas. En plena faena de edición de las Conjeturas, un primo abogado le exige eliminar pasajes que injurian post mortem a un tío abuelo en común, Eliodoro Yáñez. Insinuarían que "la abuela de ese político muerto hacía muchos años había sido, quién sabe si en el siglo XIX, una suerte de 'cabrona', regenta de un prostíbulo" (Maturana 143). Donoso accede por temor a una demanda, pero también — esta es una conjetura de Marcelo Maturana, editor de las Conjeturas en 1996-temiendo que "afloraran públicamente aspectos de su sexualidad" (144). Sea como fuera, lo concreto es que un velo de censura modifica el diseño de las Conjeturas, a pesar de Donoso. Ante esto, el escritor acentúa sus tácticas de encubrimiento.

A diferencia del gesto de su antepasado, que busca obliterar los rastros de "inmundicia", y el de autocensura del texto, el velo de Donoso oculta una ávida imaginación tras la pose de un curador de antiguos retratos. Cabe destacar que en varios momentos de la narración algunos personajes se introducen a partir de su imagen fotográfica. El velo permite, "con incertidumbres, puesto que de conjeturas se trata [...], echarle mano a este cuento" (186), movilizando así una poética translúcida.

Donoso es consciente, además, que el velo actúa en el imaginario nacional como una forma de "olvido, que no es entendimiento ni perdón y no borra nada, pero que es el 'tupido velo' que todo el mundo corre en Chile para ocultar lo molesto, lo vergonzoso, lo peligroso, y en último término la verdad" (167). Este reconocimiento, junto a la trama de la huida de Eugenia, nos lleva a tres conjeturas sobre el encierro de Marta en el convento. De acuerdo al plan inicial de Donoso, las tres habrían de desarrollarse en capítulos interdependientes de una novela. La primera indica que, con el fin de "lavar la mancha de Eugenia" (214), su hermana Marta se ofrece como chivo expiatorio y decide entrar a un convento, fiándose de los consejos de su tía Josefina Mandiola. Su madre se opone a que su hija se relacione con esa "mujer impía [...], comprometida con los radicales y los masones" (215), y 
la encierra en el convento de las Capuchinas. La segunda conjetura surge de una amiga de Donoso, "¿Qué te hace pensar que en realidad era la tía Marta la que se escondía debajo del velo negro, y no otra persona que la sustituía?" (243). A partir de este giro, Donoso elabora una tercera conjetura, fuertemente novelística.

Rumbo a Santiago en tren, Marta se retracta de ingresar al convento, sintiendo "pavor ante esa realidad. Además, el firmamento le pareció plano ahora, sin profundidad, donde no cabían ni ella ni Dios" (247). Una vez en Santiago, y ante el rechazo de su madre a su "pecaminosa inconsistencia" (247), Marta se envenena con una sobredosis de láudano. El médico certifica suicidio y el cura se niega a bendecir el cuerpo. Doña María Henríquez decide, entonces, "echarle tierra al asunto", literalmente. Entierran a Marta secretamente en un sitio eriazo, al borde de un río. Y junto a ella, también la primera conjetura. El plan se sella con la suplantación. La madre hace pasar a la Mariconilla, una de sus empleadas, como Marta, y la interna con las Capuchinas, para que nadie sepa que su hija "murió en pecado mortal" (254). Así, el "puterío de Eugenia" y el suicidio de Marta se saldan corriendo un tupido velo. Esta conjetura, además, pone en relieve el tema de la fisura social.

En efecto, la Mariconilla y Sandalio, su padre, ocupan un lugar ambiguo en la narración y en la casa de los Donoso Henríquez. Socialmente, transitan un espacio colonial en la región del Maule que combina "una vieja estirpe de 'caciques' provincianos con sus dependientes” (189). Físicamente, habitan el cuarto patio de lo huachos, "donde comenzaba el 'adentro', las vísceras de la casa, un laberinto maloliente de bodegas y soberados" (192). Este patio congrega a los hijos prematrimoniales del marido de María Henríquez y "a todo el resto de los huachos, que sus hijos procreaban en las campesinas de los fundos y en las sirvientes de la casa" (192). Es el lugar de una descendencia apócrifa, análogo al patio de figurillas religiosas mutiladas y envejecidas sirvientas en la casa de Ejercicios Espirituales del Obsceno pájaro de la noche. Disipadas las distinciones genealógicas, los sujetos que pueblan este espacio devienen suministro productivo para la continuidad de la casa, metonimia de un orden fundante patronal. Como bien señala Jean-Luc Nancy, el sujeto 
pensado como súbdito se encuentra siempre anexado a una voluntad de poder (18).

Hasta cierto punto, el ingreso al convento permite que la Mariconilla suture su ambigüedad social. Enclaustrada, adopta carta de ciudadanía en una “estirpe de caciques” sureños. Ante los desprevenidos es, de hecho, Marta Donoso Henríquez. En este sentido, Sandalio explica que eran "muchas las ventajas que el convento le presentaba a mi pobre hija. Nunca fue otra cosa que una costurerita, una criada, apenas un grado más arriba que una china" (261). Desde esta posición, el personaje concede un servicio mucho más valioso que el que prestaba en calidad de costurera. Si antes su trabajo era "hacer o remendar cientos y cientos de ojales para la población de toda la casa" (193), ahora, de modo similar, "remienda" vicariamente el vergonzante suicidio de Marta. Estar "en el lugar de otro" la emparenta, por cierto, con Marta, y también con la Manuela de El lugar sin límites, no necesariamente desde el travestismo, pero sí desde el enmascaramiento.

Con todo, salen a la superficie las sutiles complicidades entre amos y sirvientes. "En Donoso", apunta Leonidas Morales, "el poder actúa en el teatro de [dichas] relaciones [...]. La palabra del patrón narraba la historia de la sociedad que ambos habitaban, pero era el sirviente el que la construía" (Narración 98). El velo claramente refleja la "teatralidad" y la puesta en escena de estos intercambios, que ceden al empleado un protagonismo transitorio. En el convento, continúa Sandalio, “bajo el velo y escondida bajo el nombre de la señorita Marta, apoyada en la gran dote que la Mamita les daba por su hija a las Capuchinas, y a la Mariconilla para que se callara, ella se transformaba de la noche a la mañana en una verdadera señora" (261). Sin embargo, esta sustitución implica someterse a una voluntad que le confiere un señorío inexistente. Después de todo, “dar órdenes a las mochas, regodearse con la comida [y] elegir el mejor de los cueros negros de don Aurelio" son los excedentes de un poder que se mantiene inamovible, con o sin Mariconilla.

Cabe notar que cada conjetura actúa como una trama a partir de la cual se deslizan tensiones novelescas, como así también relaciones intra e intertextuales. La conjetura de la suplantación, por ejemplo, encarece la 
destitución de sujetos que a esta altura de las Conjeturas Donoso no duda en llamar "personajes" (240). Un caso evidente es Marta, cuyo cuerpo excomulgado se entierra en un basural en los extramuros de Santiago, "donde la tierra estaba blanda de podredumbre" (254). Al respecto, Rodrigo Cánovas ve un nexo de clausura entre este personaje y Mudito de El obsceno pájaro de la noche (66). Mariconilla, por su parte, es obligada a sesenta años de claustro. Condenada a ser otra, todo lo que queda de ella se reduce al hábito animalesco de "trepar por los techos y equilibrarse en las canaletas porque la creían un poco loca, un poco laucha, un poco gata [...]" (262). A diferencia de Marta, no es consciente de su destitución, aceptando con agrado los despojos de un poder finisecular.

La solidaridad entre sustitución y destitución es central en la obra de Donoso. Señala, entre otras cosas, el descentramiento de la identidad, sujeta a un devenir incierto. El jardín de al lado (1981) tematiza esta escisión si pensamos que el autor de la narración no es Julio Méndez, sino su esposa Gloria. Con ello, el escritor y su gran novela del Golpe se reducen a un diseño editorial ya convenido entre mujeres. Mucho antes, Coronación (1957) introdujo la destitución de una oligarquía que, hacia el final de la novela, pervive a través de la puesta en escena de su propia degradación. En Conjeturas y las novelas que la anteceden, los sujetos de la ficción son equiparables al carácter conjetural y ensayístico de la escritura. No son finitos; sugieren, en cambio, tesis variadas sobre su origen, motivaciones y el lugar que ocupan en la imaginación donosiana. Su escritura se ensaya y suplanta a sí misma, evadiendo un cierre definitivo. Tal y como Eugenia y Marta son erradicadas de la memoria familiar, la poética de Donoso también se desprende, por voluntad propia, de un atavismo basado en la mímesis realista y en la figuración orgánica de la obra. Coronación abre un surco experimental que parece consolidarse en las Conjeturas. 


\section{EL TEJIDO DE LA ESCRITURA Y SUS VELOS}

Con la tercera conjetura el escritor reformula las anteriores, sin desestimarlas por completo. "Estas tres conjeturas juntas proporcionan, creo yo, un cierto espesor, cierta enjundia, una posible tridimensionalidad a las situaciones, una polivalencia que es parecida al fenómeno de estar vivo" (240). La densidad y variación que destaca Donoso tienen sus bases en las propuestas narrativas de los escritores y personajes socialmente fisurados que admira, entre otros, Henry James. En El retrato de una dama (The Portrait of A Lady, 1881), el lector difícilmente obtiene una visión total de su protagonista, Isabel Archer. Aparece, más bien, y superando la mirada impresionista, como las composiciones cubistas, en constante análisis, sin alcanzar síntesis definitiva (Ferrada, "Caracterización” 107). Su retratista, consciente de que la ficción no es acopio de materiales narrativos, sino una permanente especulación estética, señala que "el arte vive de la discusión, experimentación, curiosidad, variedad de intentos, intercambio de visiones y comparación de perspectivas"3 (James 4).

Las Conjeturas, sin embargo, también entran en diálogo con las que realiza un antecesor de James, el novelista norteamericano Nathaniel Hawthorne $^{4}$ (1804-64). Se podría especular que es este quien, indirectamente, enseña a James el arte de la conjetura que introduce a la novela moderna en la experiencia de la interrogación. Donoso, por supuesto, es depositario de esta tradición. Reflexiona repetidas veces sobre este espacio exploratorio en Historia personal del “boom” (1972), mostrándose escéptico de los edificios narrativos omniscientes. ${ }^{5}$ En uno de sus fragmentos de diario de 1994, que

3 Las traducciones de los textos críticos y obras literarias en inglés pertenecen al autor del artículo.

4 Donoso conoce bien la obra de Hawthorne, principalmente a través de sus estudios de literatura en la Universidad de Princeton y de la co-traducción, junto a su esposa Pilar Serrano, de The Scarlet Letter.

5 Su escritura refleja esta desconfianza por medio de "un principio de fusión estética donde convergen y reformulan, entre otros, la subjetivación descentrada de los modernistas ingleses y el espacio de la memoria en la novela francesa" (Ferrada, "Configuración" 53). 
coincide con la escritura de las Conjeturas, considera que "los novelistas ya no tienden a pontificar ni a profetizar ni a creer que pueden explicarlo todo, sino que han vuelto a sus cometidos más o menos modestos, y sin ver el mundo y la sociedad como un gran todo" (Pilar Donoso 363). La conjetura de Donoso, en tanto techne, no busca dilucidar, sino crear espacios translúcidos provistos de indeterminación.

Tanto en La letra escarlata (The Scarlet Letter, 1850) como en "El velo negro del ministro" ("The Minister's Black Veil”, 1836) Hawthorne diseña una imagen clave, un tejido que insta, como diría Donoso, dimensiones polivalentes. En la novela, ambientada en la colonia puritana de Salem, Hester Prynne exhibe un bordado en su pecho con la letra "A", que la signa como adúltera. Pero las especulaciones del narrador y los otros personajes cambian su sentido original, percibiendo en la protagonista rasgos piadosos. Adúltera, sugiere Hawthorne, se escribe con "a" de "ángel". En el contexto de las Conjeturas encontramos aspectos similares. A Eugenia se le acusa de fugarse con el Gringo Barrow sin haber contraído matrimonio, hecho que años más tarde ella desmiente. No solo eso. Consintió que uno de sus empleados la tocara, mientras ella entornaba "sus ojos verdes, encendidos de placer y humedeciéndose a medida que los dedos del negrito avanzaban por su cuello [...]" (204). En este sentido ambas adulteran un cuerpo político, impugnando su legitimidad. Una desafiando la teocracia calvinista; la otra a "una vieja estirpe de 'caciques' provincianos" (189), casta de liberales-conservadores "adversa a cambios y adelantos, pero muy aficionada a los santos, a los sacerdotes y monjas [...]" (187). También sobresalen divergencias, y es a través de ellas que apreciamos el fino engranaje conjetural que moviliza el trabajo de Donoso.

A diferencia de Hester, obligada a exhibir su emblema en público, Eugenia oscurece en el anonimato, condenada a ser paria de la familia. Migra a San Francisco, paisaje cultural que pone a prueba los mitos fundantes de las colonias protestantes de Nueva Inglaterra: el sueño americano y la celebración del individualismo. Su padre decide echar tierra al incidente, correr un tupido velo; la madre, por su parte, resuelve enclaustrar a Marta para que pague 
la falta de su hermana. Otra distinción surge de los motivos para indagar la "falla geológica" de los personajes. A partir del comentario de un cuento de Hawthorne, J. L. Borges concluye que "el misterioso mundo de que habla, regido por leyes inexplicables, es manifiestamente el de la predestinación calvinista" (31). Para Hawthorne, la pregunta clave es saber si la falla provoca, de hecho, una alteración de esta ética, en favor de un romanticismo que confía en la libertad individual. Donoso, en cambio, tensiona la fisura con el fin de amplificar las resonancias novelescas de sus Conjeturas. "Consciencia de clase" y, desde aquí, la búsqueda de un pliegue de subjetivación y significación en el tejido de relaciones familiares, son aspectos que afectan por igual a Eugenia y Mariconilla. Desde este punto de vista, ellas no solo están sujetas a un desclasamiento que otorga a la narración un innegable atractivo novelesco, como reconoce Donoso, sino también a un trabajo escritural que desnaturaliza la idea de que la ficción deriva de un referente real. Una ficción, como la que propone el autor en el capítulo 7, proviene de historias imaginadas que no comportan una verdad empírica, sino un punto de vista, feble y provisional. Las palabras de James son oportunas cuando estima que una "novela es, en su sentido más amplio, una impresión personal de la vida; eso constituye, en primer término, su valor, mayor o menor dependiendo de la intensidad de la impresión" (8).

El comentario de Hawthorne en el capítulo introductorio a La letra escarlata, "La aduana" ("The Custom House"), es igualmente decidor. $\mathrm{Al}$ anochecer, y cuando la luz de la luna se filtra en un cuarto, los objetos pierden solidez; se perciben desde un "territorio neutral" donde "lo real se confunde con lo imaginario, cada uno absorbiendo el carácter del otro" (28). Con esta imagen crepuscular el autor acentúa la confluencia entre dos géneros narrativos, la novela y el romance. Donoso, desde luego, escribe en un ámbito que ya ha superado las convenciones adscritas a estos géneros en el siglo 19. En sus Conjeturas persiste, sin embargo, el apego por un modo de narrar que oscila entre la luz y la sombra, dialogando así con el juego visual que propone Hawthorne. Ficción y realidad se enmascaran. Aquí la imagen del velo negro se torna propicia, pues tanto en el cuento de Hawthorne como en 
el de Donoso ${ }^{6}$ este tejido participa como principal aliciente para la fantasía y la especulación imaginativas. No solo los autores, también los personajes y los lectores contribuyen a tensionar sus fibras, con el deseo de entrever qué se oculta tras este enigma. Cada desgarro del tejido constituye, además, un gesto escritural, una especulación que amplifica los bordes de la ficción. El velo en sí mismo deviene metáfora de aquella ficción.

La narración de Hawthorne teje versiones sobre lo que habría gatillado en el ministro Hooper la excentricidad de cubrir su rostro con un velo. Sobresale la idea de un fallo o pecado inconfesables. Nadie logra disuadirlo a que se lo quite, ni otros ministros protestantes ni Elizabeth, su prometida. Tampoco la proximidad de la muerte. En un último intento, el reverendo Clark "se reclinó sobre su cama para revelar el secreto por tantos años guardado. Pero con una repentina energía, que sorprendió a los presentes, el padre Hooper sacó sus manos de entre las sábanas, sujetando firmemente el velo negro, resuelto a luchar si el ministro de Westbury insistía en contradecir a un moribundo" (706).

La idea de una férrea voluntad de conservar el velo también anima una de las conjeturas de Donoso. De regreso a Santiago desde San Francisco, y al saber que su hermana agoniza en el convento, Eugenia la visita en su celda: “Al estirar su enjoyada mano para levantar el velo de Marta, sintió que otra mano, helada y débil pero firme, tomaba la suya para impedirle terminar su equivocada acción de misericordia. Eugenia sintió como si esa mano helada saliera de ultratumba para arrastrarla a ella bajo tierra" (259). Esta tenacidad revela, en ambos casos, motivaciones distintivas. La obsesión de Hooper dramatiza un tema ubicuo en la obra de Hawthorne, la separación del sujeto de sus semejantes y la comunidad. Hester, Hooper y Wakefield, personaje de un cuento homónimo, comparten esta fisura que, más allá de lo social, se vincula a una orfandad existencial. El narrador en "Wakefield" nos recuerda que en "el desorden aparente de nuestro misterioso mundo, cada hombre está

6 Repetidas veces Donoso usa el término "cuento" para referirse a sus conjeturas, acentuando el ejercicio imaginativo que las sostiene. 
ajustado a un sistema con tan exquisito rigor [...], que el individuo que se desvía un solo momento corre el terrible albur de perder para siempre su lugar" (Cit. en Borges 30). Son sujetos que no están sujetos a nada y que, creemos, anuncian la aparición del individuo en la narrativa de Hawthorne. En Donoso, la monomanía de conservar el velo sigue otra dirección. Se trata, sobre todo, de un recurso que le permite insistir y metaforizar.

Insiste en el gesto de enmascararse, que insufla vitalidad a su estética narrativa. Sobre este punto, Donoso indica que en El lugar sin límites y El obsceno pájaro de la noche se ha empeñado en "deshacer el concepto de unidad en la persona. Yo no creo en tal unidad. Mis personajes son mutaciones, y en tal condición uno de ellos puede ser dos o tres" (Godoy 29). Como Marta, que se transforma vicariamente en Eugenia; y Mariconilla, que suplanta la identidad de Marta. Ahora bien, el enmascaramiento también advierte el modo en que el autor se representa a sí mismo. "Existe otra biografía más, que es su biografía social, quien fue y quiso ser o se imaginó ser, cuál o cuáles fueron las máscaras de identidad que se le ocurrió llevar por el mundo, de quién se disfrazó para alternar con sus semejantes" (Donoso, Artículos 298). En sus Conjeturas uno de esos disfraces es el de un curador que ordena los fragmentos desgastados de retratos familiares, concienzudamente buscando una verdad incompatible con el arte de la ficción.

En el capítulo 7 ese disfraz da paso a la figuración del novelista, equipado ahora de un velo y sus metáforas. "Los cueros negros", título del capítulo, se refiere a los cueros de oveja negra que cada año el hermano de Sor Bernarda le envía al convento de la Capuchinas, "¿para recordarle que ante el mundo ella era una pecadora?" (219). Sobre estos cueros las monjas se arrodillan y oran. Para Marta, además, estas piezas sin mayor elaboración encubren un juicio moral. En cambio, la disposición de las hebras del velo sugiere una artificialidad similar al tejido de las conjeturas. La densidad del velo y su diseño actúan como una singular metáfora de que, en el espacio literario de las Conjeturas, "no existe una historia real o inequívoca" (Cit. en Edwards 10).

De aquí el acento en la imagen del velo, y en un gesto, la voluntad por 
parte de Mariconilla/Marta de nunca sacárselo. "No sólo eso: tenía sus manos crispadas sujetando el velo en su sitio, como con el deseo de impedir que alguien se lo quitara, aun después de muerta" (260). Ellas representan un cuerpo escritural reticente a las conclusiones. Sandalio, padre de la Mariconilla, retira el velo y explica, como haría un narrador omnisciente, la motivación de la hija. "La razón fue que no quería que descubrieran su verdadera identidad, que reconocieran su cara y se dieran cuenta de que no era la señorita Marta sino la pobre Mariconilla, hija del cochero Sandalio" (262). Se cumple a cabalidad la noción de que "el dolor causado por la ambigüedad social es uno de los temas que en los novelistas han dado mayores frutos" (17). Aun así, si las conjeturas sobre Sor Bernarda hubiesen derivado en una novela, Donoso no habría quedado satisfecho con la narración de Sandalio. Su relato es parte de una curaduría que une cabos sueltos, sin insistir en la especulación ficticia. Ofrece respuestas, no preguntas. Donoso, en cambio, habría incentivado enmascaramientos adicionales para sus personajes y su propia escritura. De haberse escrito, su novela sería, quizás, la primera de un chileno no solo con una monja y su velo como protagonistas, sino una de las primeras en imaginar la escritura como un cuerpo velado reticente a su desnudez.

\section{CONCLUSIONES}

Importa destacar que de las varias conjeturas sobre la imposición del velo, la que adquiere mayor relevancia es la asociada a la suplantación. Todas estas especulaciones están, por supuesto, fuertemente vinculadas. Constituyen parte de una trama compleja que aúna personajes históricos, registros de familia, hitos biográficos y la disposición narrativa del autor. Esta trama se desarrolla, a su vez, a través de géneros referenciales donde sobresalen rasgos cronísticos, ensayísticos y autobiográficos. Las Conjeturas se deslizan así en un ensamblaje discursivo que, independiente de sus grados de cercanía con la realidad, se sostiene, principalmente y sin claudicar, a partir de la imaginación literaria del autor.

Donoso nos recuerda, y a sí mismo, la falibilidad y transformación de 
las historias (de familia, o de otro orden). Algunas se convierten en mitos y rumores; otras ocupan un entramado donde los hechos se confunden con su interpretación. Pero todas se remiten unas a otras, entrelazadas novelescamente. En el taller del escritor que felizmente renuncia a la curaduría de la memoria de su tribu, las Conjeturas comienzan a ser fruto de la imaginación literaria de esas historias.

Esta imaginación es, desde luego, licenciosa. Sugiere una ambigua relación con la crónica familiar. En efecto, en las Conjeturas abundan dispositivos retóricos que confirman la veracidad de un evento, para después refutarlo o ponerlo en tela de juicio. "Por lo que recuerdo (puedo estar equivocado...)" (273), es un enunciado que, con variaciones, se repite a lo largo del texto. En estos casos, la imaginación se amplifica guiada por un tono especulativo, se encumbra incluso al "espacio novelesco" donde prevalece la emoción del autor que subjetiva el perfil de las cosas (Donoso, Artículos 115). Una vez allí, sin embargo, y cuando el lector cree que este espacio ha dejado atrás los referentes que lo inspiraron, el autor vuelve a ellos, pero sin atisbo de renunciar a sus "fantasías ancestrales" (268).

El espacio literario de las Conjeturas también encuentra un fuerte dinamismo intratextual, con un conjunto de referencias que los lectores pueden asociar a otras obras narrativas de Donoso, a su biografía literaria, y a especulaciones metarreflexivas en torno a estas fuentes. El tejido intertextual, por su parte, acrecienta la intención y el tono novelesco de las Conjeturas. En ellas concurren no solo autores frecuentemente aludidos por Donoso en sus escritos referenciales, como Henry James o Virginia Woolf, sino también el portentoso velo de Nathaniel Hawthorne que el autor tensiona estética y argumentalmente como principio de una poética escritural que, a fin de cuentas, acentúa la opacidad del enmascaramiento como el principal medio para la construcción de un espacio literario. 


\section{REFERENCIAS}

Álvarez-Rubio, P. Metáforas de la casa en la construcción de identidad nacional: cinco miradas a Donoso, Eltit, Skármeta y Allende. Santiago: Editorial Cuarto Propio, 2007.

Borges, J. L. Introducción a la literatura norteamericana. Buenos Aires: Emecé, 1997.

Cánovas, R. "Dictámenes en torno a las conjeturas donosianas". Universum. Vol. 30, $\mathrm{N}^{\circ}$ 1, 2015. 56-67.

Cerda, M. La palabra quebrada (Ensayo sobre el ensayo). Santiago: Tajamar Editores, 2005.

Donoso, J. Artículos de incierta necesidad. Ed. Cecilia García Huidobro. Santiago: Alfaguara, 1998.

. Conjeturas sobre la memoria de mi tribu. Santiago: Alfaguara, 1997.

. Cuentos. Santiago: Seix Barral, 1985.

Edwards, E. José Donoso: voces de la memoria. Santiago: Editorial Sudamericana, 1997.

Ferrada Aguilar, A. "Caracterización cubista en El retrato de una dama de Henry James". Estudios de literatura contemporánea. Ediciones Facultad de Humanidades, Universidad de Playa Ancha, 2004. 93-109. . "Configuración crítica de la novela hispanoamericana contemporánea en los ensayos de José Donoso". Nueva Revista del Pacífico. $\mathrm{N}^{\circ}$ 62, 2015. 44-72.

García Huidobro, C. "Introducción”. El escribidor intruso, José Donoso. Santiago: Ediciones UDP, 2004.

Godoy, E. "Diálogo con José Donoso". Revista Signos. № 2, 1971. 23-32. Hawthorne, N. "The Minister's Black Veil". The American Tradition in Literature. Ed. Sculley Bradley. New York: Norton, 1974. 695-706. . The Scarlet Letter. Eds. Seymour Gross et. al. New York: Norton Critical Edition, 1988. 
James, H. The Art of Fiction and Other Essays. New York: Oxford UP, 1948. 3-24.

Lombardo, M. "Autobiografía, identidad y memoria familiar. Apuntes a Conjeturas sobre la memoria de mi tribu de José Donoso. Caracol 10, Dossié.

Maturana, M. "José Donoso: la conjetura como arte narrativo". Estudios Públicos, $\mathrm{N}^{\circ} 133,2014$. 137-145.

Morales, L. "Diario de José Donoso: de la pose y del doble". Revista Chilena de Literatura, $\mathrm{N}^{\circ} 87$, Noviembre 2014. 235-253. . De muertos y sobrevivientes. Narración chilena moderna. Santiago: Cuarto Propio, 2008. . La escritura de al lado. Géneros referenciales. Santiago: Cuarto Propio, 2001.

Nancy, J-L. ¿Un sujeto? Buenos Aires: La Cebra, 2014.

Schaeffer, J-M. ¿Qué es un género literario? Madrid: Akal, 2006. 